\title{
Artikel
}

\section{De stand van de stelselherziening: de wettelijke basis voltooid}

\author{
Mr. H.W. (Wilco) de Vos*
}

\section{Inleiding}

Kort voor het zomerreces heeft de Eerste Kamer het voorstel voor de Aanvullingswet natuur ${ }^{1}$ aangenomen. Dit was het laatste wetsvoorstel voor de bouw van het stelsel dat in procedure was. Met het aannemen daarvan is de parlementaire behandeling van de formele wetgeving afgerond. Inmiddels zijn alle wetsvoorstellen tot wet verheven. Daarmee is de wettelijke basis van het stelsel voltooid.

Ook nu het formele wetgevingsproces is afgerond, blijft het parlement nauw bij de totstandkoming van het stelsel betrokken. Het accent zal komen te liggen op de zorgvuldige invoering van het stelsel. In mei heeft de minister van Binnenlandse Zaken en Koninkrijksrelaties (BZK), samen met de vertegenwoordigers van provincies, gemeenten en waterschappen, de nieuw beoogde datum van inwerkingtreding bekendgemaakt: 1 januari 2022. De komende periode zal in het parlement het debat gevoerd worden of aan de randvoorwaarden voor inwerkingtreding is voldaan. Belangrijke onderwerpen zijn de voortgang van de voorbereiding op de invoering van het stelsel en de totstandkoming van het Digitaal stelsel Omgevingswet (DSO). Deze onderwerpen kwa- men ook bij de behandelingen van de wetsvoorstellen aan bod. Dit heeft geleid tot een groot aantal toezeggingen over informatievoorziening in aanloop naar de inwerkingtreding en daarna. De definitieve afweging over het moment van inwerkingtreding zal worden gemaakt bij het debat over het ontwerp van het inwerkingtredings-KB van de Omgevingswet.

Parallel daaraan wordt de uitvoeringsregelgeving van het stelsel verder afgebouwd. $\mathrm{Na}$ de voorhangprocedure bij het parlement zijn de ontwerpen van het Invoeringsbesluit en de aanvullingsbesluiten voor advies voorgelegd aan de Afdeling advisering van de Raad van State. Over enkele ontwerpen heeft de Raad inmiddels advies uitgebracht. Naar verwachting zullen eind van het jaar alle amvb's zijn vastgesteld. Ten slotte zijn ook alle aanvullingsregelingen in consultatie gegaan. De internetconsultatie van de Aanvullingsregeling geluid, in het bijzonder de vernieuwde rekenregels voor gecumuleerd geluid, heeft tot veel reacties geleid. Juist op het concrete niveau van de uitvoeringsregelgeving komen de verschillende belangen binnen de leefomgeving, zoals woningbouw, luchthavens en de bescherming tegen geluidhinder, expliciet naar voren.

Dit artikel bevat een kort overzicht van de parlementaire behandeling en een vooruitblik op het vervolg van de stelselherziening dit najaar.

* Mr. H.W. de Vos is werkzaam bij de directie Constitutionele Zaken en Wetgeving van het Ministerie van Binnenlandse Zaken en Koninkrijksrelaties en is als juridisch projectleider betrokken bij de totstandkoming van de nieuwe omgevingswetgeving. Het artikel is op persoonlijke titel geschreven.

1. De volledige citeertitel van de Invoeringswet, het -besluit en -regeling en de aanvullingswetten, -besluiten en -regelingen is met de toevoeging 'Omgevingswet'. Die toevoeging blijft in dit artikel achterwege. 


\section{Overzicht van de}

\section{parlementaire behandeling van de wetgeving}

\begin{tabular}{lll}
\hline & $\begin{array}{l}\text { Kamerstuk- } \\
\text { nummer }\end{array}$ & Staatsblad \\
\hline Omgevingswet & 33962 & 2016,156 \\
\hline Invoeringswet & 34986 & 2020,172 \\
\hline Aanvullingswet geluid & 35054 & 2020,83 \\
\hline Aanvullingswet bodem & 34864 & 2020,87 \\
\hline Aanvullingswet natuur & 34985 & 2020,310 \\
\hline $\begin{array}{l}\text { Aanvullingswet grond- } \\
\text { eigendom }\end{array}$ & 35133 & 2020,112 \\
\hline
\end{tabular}

De Eerste Kamer heeft het afgelopen parlementaire jaar vijf wetsvoorstellen en de bijbehorende vijf ontwerpbesluiten behandeld. Inmiddels zijn de wetsvoorstellen tot wet verheven en in het Staatsblad gepubliceerd. Daarmee zijn op wetsniveau alle onderdelen van het stelsel door de formele wetgever afgerond. Deze zijn in onderstaand schema opgesomd. ${ }^{2}$

Zoals in de vorige aflevering van deze serie artikelen is beschreven, hebben beide Kamers de wetsvoorstellen uitgebreid behandeld. Dit heeft geleid tot brede parlementaire steun. Vrijwel alle wetsvoorstellen van de stelselherziening zijn, zowel in de Tweede Kamer als in de Eerste Kamer, met meer dan twee derde meerderheid aangenomen. ${ }^{3}$ Voor de stabiliteit en continuiteit van de stelselherziening is dit brede draagvlak van groot belang.

Buiten het bouwproces van het nieuwe stelsel zijn voor de inwerkingtreding van het nieuwe stelsel twee andere wetstrajecten relevant. Dit betreft de wijziging van de Bekendmakingswet (de Wet elektronische publicaties $(\mathrm{Wep})^{4}$ ) en de wijziging van de Algemene wet bestuursrecht $(A w b)$ in verband met het nieuwe omgevingsrecht en nadeelcompensatierecht. ${ }^{5}$ Deze wetsvoorstellen hebben een bredere bestuursrechtelijke betekenis en wijzi-

2. De wetten staan in de volgorde waarin deze (afgezien van enkele onderdelen) op de beoogde datum (1 januari 2022) in werking zullen treden. Deze volgorde zal bij KB worden bepaald.

3. Het voorstel voor de Aanvullingswet grondeigendom is in de Tweede Kamer met 93 stemmen (62\%) voor aangenomen. In de Eerste Kamer hebben 53 leden (71\%) voor dat wetsvoorstel gestemd.

4. Het bij koninklijke boodschap van 6 juni 2019 aangeboden voorstel van wet tot wijziging van de Bekendmakingswet en andere wetten in verband met de elektronische publicatie van algemene bekendmakingen, mededelingen en kennisgevingen (Wet elektronische publicaties) (Kamerstukken 35 218).

5. Het bij koninklijke boodschap van 10 juli 2019 aangeboden voorstel van wet tot wijziging van de Algemene wet bestuursrecht en enkele andere wetten in verband met het nieuwe omgevingsrecht en nadeelcompensatierecht (Kamerstukken 35 256). gen ook de Omgevingswet. De wijzigingen van de Omgevingswet zullen tegelijk met het nieuwe stelsel in werking treden. In juni is het voorstel voor de Wep door de Eerste Kamer met algemene stemmen aanvaard. Het voorstel is inmiddels tot wet verheven en bekendgemaakt (Stb. 2020, 262). ${ }^{6}$ Het voorstel voor de wijziging van de Awb is op dit moment bij de Tweede Kamer aanhangig. De parlementaire behandeling daarvan loopt dus nog.

Behandeling wetsvoorstel Aanvullingswet natuur De plenaire Eerste Kamerbehandeling van het voorstel voor de Aanvullingswet natuur vond plaats in de Ridderzaal, de tijdelijke vergaderlocatie van de senaat vanwege de coronamaatregelen. De minister van Landbouw, Natuur en Voedselkwaliteit (LNV) (Schouten) nam als primair inhoudelijk verantwoordelijke de beantwoording van de vragen over de natuurregelgeving voor haar rekening. Net als bij de Tweede Kamerbehandeling werden de vragen over het stelsel beantwoord door de Minister van BZK als stelselverantwoordelijke minister. Dit was een verschil met de plenaire behandelingen in de Eerste Kamer van de voorstellen voor de Invoeringswet en de andere aanvullingswetten. Die waren, tijdens de afwezigheid van minister Ollongren, met de Minister voor Milieu en Wonen (Van Veldhoven).

Voor en tijdens de behandeling was er aandacht voor de relatie met eindadvies van het Adviescollege Stikstofproblematiek. ${ }^{7}$ De regering heeft aangegeven dat de Aanvullingswet natuur zorgt voor de inbouw van de bestaande natuurregels in het stelsel van de Omgevingswet. De wijzigingen in verband met de structurele aanpak van stikstof zullen worden opgenomen in het wetsvoorstel stikstofreductie en natuurverbetering en de daaraan verbonden amvb. Daarbij zullen die regels tevens in het nieuwe stelsel worden ingepast. Hierover zal afzonderlijke gedachtewisseling met de Tweede en de Eerste Kamer plaatsvinden. ${ }^{8}$ Wel heeft de regering nu al duidelijk gemaakt welke onderdelen van het ontwerp-Aanvullingsbesluit natuur zullen worden geschrapt aangezien die nog betrekking hebben op de programmatische anpak stikstof (PAS). ${ }^{9}$

Bij de meeste Kamerleden was er begrip om de bestaande regels beleidsneutraal in het nieuwe stelsel in te bouwen. Niettemin kwamen tijdens de behandeling diverse onderwerpen aan bod die betrekking hadden op de actuele stand van de kwaliteit van de natuur en de noodzaak tot bescherming. Er werd een verband gelegd met de selectie, de aanwijzing en de doelen van Natura 2000gebieden, de realisatie van het Nationaal Natuurnetwerk, de invoering van een resultaatsverplichting in plaats van een streefwaarde voor stikstof, de mogelijkheid van salderen en natuurcompensatie. Het voert in

6. Dat geldt ook voor een daarmee samenhangende wijziging in verband met de aansluiting op de Omgevingswet die is opgenomen in: Stb. 2020, 211.

7. Kamerstukken I 2019/20, 35 334, Q

8. Kamerstukken I 2019/20, 35 334, T, p. 3.

9. Kamerstukken I 2019/20, 35 334, T, p. 4. 
het kader van deze rubriek te ver om op deze onderwerpen inhoudelijk in te gaan. In relatie tot het nieuwe stelsel kwam met name de verhouding aan de orde tussen de Europeesrechtelijke kaders voor natuur en de afwegingsruimte binnen het stelsel. Ook wezen diverse sprekers op de samenhang van natuur en andere maatschappelijke opgaven. De ministers onderschreven dat met de integratie van de natuurregels, bijvoorbeeld in het omgevingsplan, die samenhang wordt versterkt en het belang van natuur 'aan de voorkant' kan worden meegewogen.

Een meer algemeen punt had betrekking op de evaluatie van de Omgevingswet. Vrijwel Kamerbreed was er een wens dat de voorziene onafhankelijke evaluatiecommissie gedurende vijf jaar jaarlijks rapporteert aan de Staten-Generaal over de uitvoering van de wet. Hierover is een motie ingediend. ${ }^{10}$ Minister Ollongren gaf aan dat dit zou kunnen op basis van de jaarlijkse monitoring van onderwerpen en waardeerde de motie met 'oordeel Kamer'. In een korte derde termijn vroeg PvdAsenator Recourt minister Schouten of zij bereid was bij de jaarlijkse rapportage het functioneren te betrekken van de samenwerking tussen de centrale en decentrale overheden (in het bijzonder de wijze waarop de ambities op het terrein van natuurbescherming en versterking wel of niet worden gehaald). Minister Schouten zegde dit toe. Daarop heeft de Eerste Kamer de motie en het wetsvoorstel aangenomen. ${ }^{11}$

\section{Parlementaire behandeling van het vervolg van de stelselherziening}

\section{Toezeggingen}

Tijdens de debatten van het afgelopen jaar is door de verantwoordelijke bewindspersonen ${ }^{12}$ een groot aantal toezeggingen gedaan. Deze toezeggingen zijn van belang voor het vervolg van de stelselherziening en de informatievoorziening aan het parlement. Deze richten zich niet alleen op de periode tot inwerkingtreding maar ook op monitoring en evaluatie daarna. Een totaalover-

10. Kamerstukken I 2019/20, 34 985, K.

11. De motie is met algemene stemmen aangenomen. Voor het wetsvoorstel waren er 58 stemmen voor: VVD, FVD, CDA, D66, PvdA, PVV, ChristenUnie, 50PLUS, SGP en OSF, en 17 stemmen tegen: GroenLinks, $\mathrm{SP}, \mathrm{PvdD}$ en Fractie-Otten.

12. De debatten zijn gevoerd door de stelselverantwoordelijke minister en bij de aanvullingswetten tevens door de primair inhoudelijk verantwoordelijke bewindspersoon. Voor de Aanvullingswet natuur was dat bijvoorbeeld de Minister van LNV. Tijdens de ziekte van minister Ollongren was de stelselverantwoordelijkheid voor de Omgevingswet tijdelijk belegd bij de Minister voor Milieu en Wonen (Van Veldhoven). Zie het besluit van 1 november 2019 (Stcrt. 2019, 61106). Sinds 14 april 2020 wordt de stelselverantwoordelijkheid weer uitgeoefend door de Minister van BZK. Zie het besluit van 10 april 2020 (Stcrt. 2020, 22571). zicht en de stand van zaken daarvan is opgenomen in de brief van 28 september $2020 .^{13}$

\section{Informatievoorziening}

Buiten de parlementaire behandeling van de diverse wetsvoorstellen is een groot aantal brieven en documenten aan het parlement gezonden. Deze stukken verschijnen onder het algemene Kamerstuknummer van de stelselherziening omgevingsrecht (33 118). Een belangrijke brief was de brief over de nieuw beoogde datum van inwerkingtreding. ${ }^{14}$ De nieuwe datum moet de benodigde ruimte bieden voor de afronding van het wetgevingsproces en de ontwikkeling van het DSO en voldoende tijd geven aan de uitvoeringspraktijk om zich voor te bereiden op de inhoud van de wet- en regelgeving en om met het nieuwe digitale stelsel te oefenen. Deze brief ging vergezeld van een verklaring van de VNG, de Unie van Waterschappen, het IPO en het Rijk, waarin deze partijen uitspreken zich gezamenlijk in te zullen zetten voor een zorgvuldige implementatie en uitvoering van de Omgevingswet. Uit de verklaring blijkt ook dat het de bedoeling is om de Wet kwaliteitsborging voor het bouwen tegelijk met de Omgevingswet, dus op 1 januari 2022, in werking te laten treden. ${ }^{15}$ Op die manier kan de uitvoeringspraktijk de implementatie van beide wetstrajecten in samenhang voorbereiden.

Vast onderdeel van de informatievoorziening aan het parlement vormen de voortgangsbrieven, die inzicht bieden in de stand van zaken van de implementatie en de voortgang van het $\mathrm{DSO}$. $\mathrm{Nu}$ de datum van inwerkingtreding dichterbij komt, is de frequentie daarvan toegenomen. Ook is de hoeveelheid informatie uitgebreid, onder andere met cijfers over de aansluiting van overheidsorganisaties op het DSO (aansluitmonitor DSO). ${ }^{16}$ De voortgangsbrief van 24 juni bevat daarnaast ook andere informatie, zoals een nulmetingsrapportage over de rechtspraak door het CBS. ${ }^{17}$ Eerder was al een nulmetingsrapportage toegezonden over vergunningen en meldingen. ${ }^{18}$ Deze rapportages (op basis van het huidige omgevingsrecht) kunnen worden gebruikt als basis voor toekomstige monitoring en evaluatie van de wet.

Dit najaar volgt wederom een voortgangsbrief met de laatste monitoringsinformatie en een advies van Bureau ICT-toetsing (BIT) met een beleidsreactie daarop. Ook volgt nog informatie over financiële aspecten van de invoering van de Omgevingswet. Deze informatie kan worden betrokken bij de afweging over de datum van inwerkingtreding van de Omgevingswet. Vervolgens kan het parlement bij de voorhang van het ontwerp van

13. Kamerstukken I 2020/21, 33 118, BG, p. 5 ev

14. Kamerstukken II 2019/20, 33 118, nr. 145 en Kamerstukken I 2019/20, 33 118, BE.

15. Ibid. (bijlage)

16. De actuele cijfers zijn te vinden via de website www.aandeslagmetde omgevingswet.nl.

17. Monitor Escalaties Omgevingsrecht. Kamerstukken II, 2019/20, 33 118, nr. 148, p. 11 en bijlage 5.

18. Kamerstukken I 2019/20, 33 118, BD, p. 4 en bijlage 3. 
het inwerkingtredings-KB voor de Omgevingswet de balans opmaken. ${ }^{19}$ Daarna kan het inwerkingtredings$\mathrm{KB}$ worden vastgesteld. Tijdige vaststelling is van belang aangezien er dan duidelijkheid is voor de uitvoeringspraktijk.

\section{Monitoring, evaluatie}

De toezeggingen waren niet alleen gericht op informatievoorziening in aanloop naar inwerkingtreding van het stelsel maar ook op de monitoring en evaluatie van de werking van het stelsel in de praktijk. In de brief van 24 juni worden enkele onderwerpen genoemd die na inwerkingtreding van het stelsel zullen worden gemonitord, zoals de algemene balans tussen beschermen en benutten, de verbeterdoelen, de werking van de kerninstrumenten, rechtsbescherming en rechtspraak. Deze onderwerpen zullen nog nader worden uitgewerkt. Voor de evaluatie zal een brede, onafhankelijke evaluatiecommissie worden ingesteld met de opdracht om vijfjaarlijks een wettelijke evaluatie van de Omgevingswet uit te voeren. De commissie zal ook adviseren over de opzet en inrichting van de monitoring en zal de uitkomsten van de monitoringsresultaten betrekken bij haar evaluatieonderzoek.

\section{Regeringscommissaris Omgevingswet}

Tot slot maakt de minister bekend dat zij voornemens is om een regeringscommissaris Omgevingswet in te stellen. ${ }^{20}$ Deze zal adviseren over de borging en verdere ontwikkeling van het wettelijke stelsel van de Omgevingswet. Dit sluit aan bij de aanbeveling uit het eindadvies van de integrale onafhankelijke adviescommissie Omgevingswet, Recht doen aan de Omgeving(swet). ${ }^{21} \mathrm{Het}$ zal gaan om een tijdelijke instelling voor een periode van vijf jaar. De adviezen zijn tijdens de transitieperiode bedoeld als extra borging van de kwaliteit en integriteit van het wettelijke stelsel en om de potentie van het stelsel optimaal te benutten.

\section{Vervolg van de wetgeving van de stelselherziening}

\section{Afbouw van de uitvoeringsregelgeving van het stelsel}

De ontwerpen van het Invoeringsbesluit en de aanvullingsbesluiten zijn voorgelegd aan de Afdeling advisering van de Raad van State. De Afdeling heeft inmiddels advies uitgebracht over de ontwerpen van het Invoeringsbesluit en de Aanvullingsbesluiten geluid, bodem en grondeigendom. ${ }^{22}$ Dit najaar zullen de adviezen openbaar worden samen met de reactie van de regering

19. In art. 23.10, tweede lid, van de Omgevingswet (zoals dat wordt ingevoegd via de Invoeringswet) is bepaald dat het ontwerp van het KB niet ter bekrachtiging aan de Koning zal worden voorgelegd als een van beide Kamers zich daarmee niet kan verenigen.

20. Kamerstukken II, 2019/20, 33 118, nr. 148, p. 11

21. Kamerstukken II, 2019/20, 33 118, nr. 123, bijlage 1.

22. https://www.raadvanstate.nl/adviezen/?

zoeken=true\&zoeken_term=omgevingswet\&pager_rows $=10$. (het nader rapport). Dan zullen ook de definitieve versies in het Staatsblad worden gepubliceerd. Daarmee is de regelgeving voor de bouw van het stelsel op amvbniveau afgerond.

De Invoeringsregeling en de aanvullingsregelingen vormen het sluitstuk van de stelselherziening. De internetconsultatie van die regelingen is inmiddels afgerond, zodat de ontvangen reacties kunnen worden verwerkt. Het voorstel voor de Invoeringsregeling is ter notificatie van de daarin opgenomen technische voorschriften aan de Europese Commissie gezonden. De consultatie van de nieuwe conceptregels van de Aanvullingsregeling geluid $^{23}$ over de berekening en kwalificatie van gecumuleerd geluid (inclusief luchtvaartgeluid als er sprake is van meerdere geluidbronnen) heeft tot veel reacties geleid. Voor regio's rondom luchthavens kunnen de nieuwe regels voor het gecumuleerde geluid leiden tot de kwalificatie 'slecht', hetgeen volgens diverse organisaties verenigd in de Woningbouwalliantie belemmerend werkt bij het realiseren van de woningbouwopgave. ${ }^{24}$ Het vervolg daarvan vergt dan ook nader overleg. De regelingen zullen, na de verwerking van de inspraakreacties, in de Staatscourant worden gepubliceerd zodra de bijbehorende amvb in het Staatsblad is verschenen. Dan zijn ook op regelingsniveau het hoofdspoor, invoeringsspoor en de aanvullingssporen gereed.

Tot slot vloeien uit de parlementaire behandeling van de stelselherziening nog twee wijzigingen van de uitvoeringsregelgeving voort. Het gaat om een wijziging van het Omgevingsbesluit in verband met het aanwijzen van categorieën ontwikkelingen waarvoor financiële bijdragen kunnen worden verhaald. Dit als gevolg van het amendement Ronnes c.s. bij het voorstel voor de Aanvullingswet grondeigendom. ${ }^{25}$ De indieners van het amendement hebben beoogd dat gemeenten financiële bijdragen kunnen vragen voor ontwikkelingen als kwalitatieve verbeteringen van landschap, natuur, water of de stikstofbalans, de aanleg of aanpassingen van infrastructuur en daartoe benodigde voorzieningen, de realisatie van sociale woningbouw buiten het plangebied en het slopen van opstallen in geval van bijvoorbeeld een krimpopgave. In het Omgevingsbesluit zullen de categorieën worden aangewezen waarvoor de bevoegdheid kan worden ingezet. De daadwerkelijke toepassing ervan is aan de gemeente en geschiedt in het omgevingsplan.

De tweede wijziging vloeit voort uit het amendement Bisschop-Ronnes ${ }^{26}$ bij de Invoeringswet Omgevingswet. Dat amendement voorziet in een redelijke gebruiksvergoeding bij de oplegging van gedoogplichten. Het betreft een vergoeding voor het feit dat de eigenaar of rechthebbende grond in gebruik geeft aan een initiatief-

23. https://www.internetconsultatie.nl/ aanvullingsregeling_geluid_omgevingswet.

24. https://www.telegraaf.nl/nieuws/1925439544/nieuwe-geluidsregelszetten-streep-door-bouw-380-000-huizen, https://www.cobouw.nl/ bouwbreed/nieuws/2020/07/woningbouw-stagneert-door-nieuwegeluidsregels-101286796

25. Kamerstukken II 2019/20, 35 133, nr. 34

26. Kamerstukken II 2018/19, 34 986, nr. 22. 
nemer. Dit leidt uiteindelijk tot een wijziging van de Omgevingsregeling. De afgelopen maanden zijn de ontwerpen van beide wijzigingen voor internetconsultatie gepubliceerd. ${ }^{27}$

Andere ontwikkelingen in de wet- en regelgeving Ondertussen staat ook buiten de stelselherziening de wereld niet stil. Er komt op diverse beleidsterreinen regelgeving tot stand die ook onderdelen van het stelsel wijzigt. Dat gebeurt bijvoorbeeld bij de implementatie van Europese wet- en regelgeving. Voorbeelden daarvan zijn de wijzigingen van het Bouwbesluit 2012 en het Besluit bouwwerken leefomgeving, onder andere in verband met bijna energieneutraal bouwen (Stb. 2019, 501 en Stb. 2020, 84). Deze regelgeving bevat zowel wijzigingen van het huidige recht als van het toekomstige nieuwe stelsel. Deze aanpak leidt ertoe dat wijzigingen, waar nodig en wenselijk, nog onder het huidige recht in werking kunnen treden. Deze zijn niet afhankelijk van de inwerkingtreding van de Omgevingswet en omgekeerd is de inwerkingtreding Omgevingswet niet afhankelijk van de beoogde wijzigingen. Deze wijzigingen zijn onderwerp van separate politieke besluitvorming. Een voorbeeld van een wijziging die is aangekondigd en waarin deze aanpak zal worden gevolgd is het voorstel voor de Wet stikstofreductie en natuurverbetering. Dat voorstel is op 15 juli jl. voorgelegd aan de Afdeling advisering van de Raad van State. ${ }^{28}$

\section{Verder met de stelselherziening}

Ondanks het uitstel van de inwerkingtreding en de coronamaatregelen is het werk aan de stelselherziening de afgelopen maanden doorgegaan. Dat gold ook voor de parlementaire behandeling. In de Ridderzaal heeft de Eerste Kamer het laatste aanvullingswetsvoorstel (natuur) plenair behandeld en aangenomen. Voortgang was er verder bij de totstandkoming van uitvoeringsregelgeving. Alle ontwerpbesluiten zijn inmiddels voorgelegd aan de Afdeling advisering Raad van State en alle ontwerpregelingen zijn voor consultatie op internet gepubliceerd.

De totstandkoming van de wet- en regelgeving schept steeds meer duidelijkheid over hoe het stelsel eruit komt te zien. Voor een totaloverzicht zijn geconsolideerde versies beschikbaar van zowel de Omgevingswet, de vier amvb's als de Omgevingsregeling. De actuele versies zijn voortaan te vinden op www.aandeslagmetde omgevingswet.nl. ${ }^{29}$ Daar zijn ook tal van webinars en webcolleges te vinden die tijdens de lockdown zijn

27. https://www.internetconsultatie.nl/besluitfinancielebijdragen. https:// www.internetconsultatie.nl/regelinggebruiksvergoeding.

28. https://www.raadvanstate.nl/adviezen/? zoeken=true\&zoeken_term=stikstof\&pager_rows $=10$.

29. De inhoud van de site www.omgevingswetportaal.nl zal daarnaar worden overgebracht. georganiseerd. ${ }^{30}$ Verder biedt die site veel informatie over de implementatie bij andere overheden en over de stand van zaken van andere onderdelen van de stelselherziening. Zo heeft een aantal provincies de afgelopen maanden een ontwerp van de omgevingsverordening in procedure gebracht. ${ }^{31}$ Daarmee krijgt ook de decentrale regelgeving van het stelsel gestalte. De meeste provincies hebben al een provinciale omgevingsvisie opgesteld. De nationale omgevingsvisie (NOVI) is inmiddels vastgesteld en aan de Tweede Kamer gezonden. ${ }^{32}$ Vervolgens kan de Kamer hierover een debat houden. De gebiedsgerichte uitvoering van de NOVI gebeurt aan de hand van omgevingsagenda's voor de vijf landsdelen. Eind juni is de eerste omgevingsagenda, voor landsdeel Oost, vastgesteld. ${ }^{33}$

Zoals in dit artikel is beschreven, is met de totstandkoming van de Aanvullingswet natuur de wettelijke basis van het stelsel voltooid. Deze bestaat uit de Omgevingswet met inbegrip van de Invoeringswet en de aanvullingswetten. Op basis daarvan kan verder worden gewerkt aan de afbouw van de regelgeving van het stelsel. Verder zal het parlementaire debat gevoerd worden over een zorgvuldige invoering. Dat gaat ook over de vraag of de uitvoeringspraktijk en het digitale stelsel tijdig gereed zijn om het stelsel in werking te laten treden. Op dat vlak gebeurt er veel, zo blijkt uit de diverse voortgangsbrieven aan het parlement. Dat krijgt de komende tijd een vervolg. De wetten zijn klaar, het werk aan de stelselherziening gaat door.
30. https://aandeslagmetdeomgevingswet.nl/implementatie/ ondersteuning/cursus-en-training/webcolleges-webinars/

31. Zie voor een voorbeeld: https://www.zuid-holland.nl/actueel/ omgevingsbeleid/ontwerp-zuid-hollandse-omgevingsverordening/.

32. Kamerstukken II 2019/20, 34 682, nr. 53.

33. https://www.tweedekamer.nl/kamerstukken/brieven_regering/detail? id=2020Z12997\&did=2020D27744https:// www.denationaleomgevingsvisie.nl/publicaties/onderzoeken+en +adviezen+publicaties/default.aspx\#folder=1643916. 